\title{
Basal levels of AMPA receptor GluAl subunit phosphorylation at threonine 840 and serine 845 in hippocampal neurons
}

\author{
Walter E. Babiec, ${ }^{1,4}$ Ryan Guglietta, ${ }^{2,4}$ and Thomas J. O'Dell ${ }^{1,3}$ \\ ${ }^{7}$ Department of Physiology, David Geffen School of Medicine at UCLA, Los Angeles, California 90095, USA; ${ }^{2}$ Interdepartmental Ph.D. \\ Program for Neuroscience at UCLA, Los Angeles, California 90095, USA; ${ }^{3}$ UCLA Integrative Center for Learning and Memory, Brain \\ Research Institute, Los Angeles, California 90095, USA
}

\begin{abstract}
Dephosphorylation of AMPA receptor (AMPAR) GluAl subunits at two sites, serine 845 (S845) and threonine 840 (T840), is thought to be involved in NMDA receptor-dependent forms of long-term depression (LTD). Importantly, the notion that dephosphorylation of these sites contributes to LTD assumes that a significant fraction of GluAl subunits are basally phosphorylated at these sites. To examine this question, we used immunoprecipitation/depletion assays to estimate the proportion of GluAl subunits basally phosphorylated at S845 and T840. Although dephosphorylation of S845 is thought to have a key role in LTD, our results indicate that few GluAl subunits in hippocampal neurons are phosphorylated at this site. In contrast, $\sim 50 \%$ of GluAl subunits are basally phosphorylated at T840, suggesting that dephosphorylation of this site can contribute to the down-regulation of AMPAR-mediated synaptic transmission in LTD.
\end{abstract}

Phosphorylation-dependent changes in the trafficking and channel properties of AMPA type glutamate receptors (AMPARs) are thought to have an important role in long-lasting forms of synaptic plasticity involved in learning and memory (Lee et al. 2003; Derkach et al. 2007; Shepherd and Huganir 2007). These receptors are tetramers formed by heteromeric (and in some cases homomeric) combinations of four homologous subunits known as GluA1-4 (Traynelis et al. 2010). Although phosphorylation sites have been identified in all of these subunits (see Traynelis et al. 2010), GluA1 subunits contain a number of sites regulated by protein kinases and phosphatases involved in NMDA receptor (NMDAR)-dependent forms of synaptic plasticity (Lee and Kirkwood 2011; Lu and Roche 2012). For example, serine 845 (S845) in the cytoplasmic carboxy-terminal tail of GluA1 subunits is dephosphorylated following the induction of long-term depression (LTD), suggesting that this site is an important target of the protein phosphatases that mediate LTD (Lee et al. 1998, 2000). Indeed, S845 phosphorylation regulates membrane trafficking of AMPA receptors (Ehlers 2000; Oh et al. 2006) and dephosphorylation of this site may contribute to the endocytosis of AMPARs that occurs in LTD (Man et al. 2007). Moreover, LTD is disrupted in mutant mice where S845 is replaced with a nonphosphorylatable alanine (Lee et al. 2003, 2010; He et al. 2011). Phosphorylation of GluA1 subunits at a nearby site, threonine 840 (T840), enhances the conductance of AMPAR ion channels (Jenkins et al. 2014), and this site is also dephosphorylated in LTD (Delgado et al. 2007; Babiec et al. 2014; Gray et al. 2014). Thus, dephosphorylation of T840 may also have a role in LTD. Interestingly, and somewhat paradoxically, LTD can still be induced in CA1 pyramidal cells expressing AMPA receptor GluA1 subunits that lack the entire carboxy-terminus (Granger and Nicoll 2014) and in hippocampal slices from GluA1 null mutant mice (Selcher et al. 2012). This suggests that dephosphorylation of GluA1 subunits at T840 and/or S845 is unlikely to be sufficient for LTD and instead has

\footnotetext{
${ }^{4}$ These authors contributed equally to this work. Corresponding author: todell@mednet.ucla.edu Article is online at http://www.learnmem.org/cgi/doi/10.1101/Im.040675.115.
}

an important modulatory role in the induction and/or expression of LTD.

The notion that dephosphorylation of GluA1 at S845 and T840 contributes to LTD assumes that a significant fraction of AMPARs are basally phosphorylated at these sites. The majority of studies examining changes in GluA1 T840 and S845 phosphorylation in LTD have, however, only measured relative changes in protein phosphorylation, and little is known about the total number of GluA1 subunits or receptors phosphorylated at these sites. Moreover, the few studies that examined this question have found highly variable results. For example, estimates of the proportion of GluA1 subunits basally phosphorylated at S845 in hippocampal neurons range from $15 \%$ (Oh et al. 2006) to as little as $0.02 \%$ (Hosokawa et al. 2015). Even less is known regarding the proportion of GluA1 subunits phosphorylated at T840, although results from a recent study indicate that only $4 \%$ of all GluA1 subunits are basally phosphorylated at this site (Hosokawa et al. 2015). Thus, it remains unclear whether basal levels of GluA1 T840 and/or S845 phosphorylation are sufficient to support the hypothesis that dephosphorylation of these sites contributes to the downregulation of AMPAR-mediated synaptic transmission that occurs in LTD.

Here, we report the results of experiments using immunodepletion assays to measure GluA1 phosphorylation in hippocampal neurons. In these assays the proportion of GluA1 subunits phosphorylated at T840 or S845 was determined by comparing total GluA1 levels in homogenates before and after immunoprecipitation with phospho-site specific antibodies to remove T840- or S845-phosphorylated subunits (Fig. 1). Using this approach we were unable to detect S845-phosphorylated GluA1 subunits suggesting that few GluA1 subunits are basally phosphorylated at this site. However, consistent with a potential role for GluA1

(C) 2016 Babiec et al. This article is distributed exclusively by Cold Spring Harbor Laboratory Press for the first 12 months after the full-issue publication date (see http://learnmem.cshlp.org/site/misc/terms.xhtml). After 12 months, it is available under a Creative Commons License (AttributionNonCommercial 4.0 International), as described at http://creativecommons. org/licenses/by-nc/4.0/. 


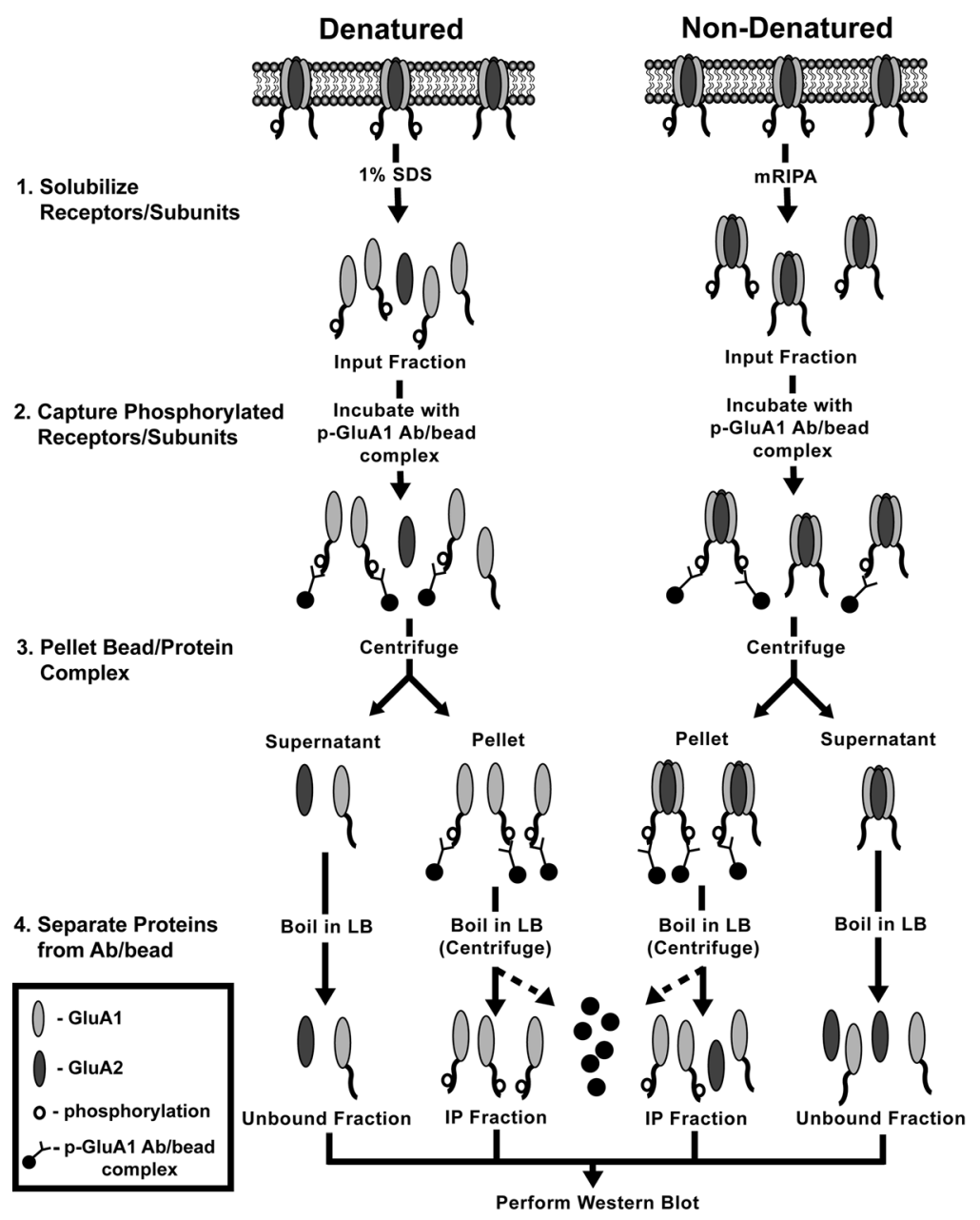

Figure 1. Schematic of immunoprecipitation/depletion assays using denatured (left) and nondenatured homogenization buffers (right). The starting material for immunoprecipitation (input fraction) consists of either individual subunits obtained from denatured homogenates prepared using $1 \%$ sodium dodecyl sulfate (SDS) buffer or intact receptors obtained from nondenatured homogenates prepared in modified radioimmunoprecipitation assay (mRIPA) buffer (Step 1). The input fraction (containing phosphorylated and nonphosphorylated subunits) is incubated with phospho-T840 or phospho-S845-specific antibodies ( $\mathrm{p}$-GluA1 Ab) conjugated to protein A coated agarose beads (Step 2). Beads (and attached proteins) are then pelleted by centrifugation, leaving nonphosphorylated subunits/receptors in the supernatant/unbound fraction (Step 3). The pelleted fraction is then resuspended in loading buffer (LB) and boiled to release proteins and antibodies (not shown) from the beads (Step 4). Phosphorylated subunits are collected by taking the supernatant following centrifugation (IP fraction). Western immunoblotting is then used to compare total GluA1 levels in the input and unbound fractions and the depletion of GluA1 levels in the unbound fraction is used to determine the proportion of subunits/receptors basally phosphorylated at each site. For simplicity, only GluA $1 / 2$ subunitcontaining heteromeric AMPARs are shown.

T840 dephosphorylation in LTD, we find that $~ 50 \%$ of GluA1 subunits are basally phosphorylated at T840.

\section{Results}

Immunoprecipitation of AMPAR GluAl subunits from denatured and nondenatured hippocampal homogenates

In our experiments we used both denatured and nondenatured homogenates for immunodepletion assays. The depletion of GluA1 subunits following immunoprecipitation of phosphorylated GluA1 under these conditions provides different, but comple- mentary, information regarding GluA1 subunit phosphorylation. When proteins are denatured prior to immunoprecipitation, the depletion of GluA1 from the homogenate represents the proportion of GluA1 subunits phosphorylated at a particular site (Fig. 1) but does not provide information regarding how these subunits are incorporated into receptors. In contrast, receptor complexes will remain largely intact in nondenatured homogenates and nonphosphorylated subunits will coimmunoprecipitate with phosphorylated subunits (Fig. 1). Thus, the depletion of GluA1 from nondenatured homogenates reflects the proportion of subunits (phosphorylated and nonphosphorylated) that reside in receptors containing at least one phosphorylated subunit.

To validate this approach we first examined the ability of a GluA1 antibody that recognizes both phosphorylated and nonphosphorylated GluA1 (i.e., total GluA1) to immunoprecipitate GluA1 and coimmunoprecipitate GluA2 subunits from nondenatured and denatured hippocampal homogenates (Fig. 2). Because the majority of AMPARs expressed by hippocampal neurons are GluA1/GluA2 heteromers (Wenthold et al. 1996; Sans et al. 2003; Reimers et al. 2011; also see Cheng et al. 2006; Lu et al. 2009), GluA1 immunoprecipitation from nondenatured homogenates should coimmunoprecipitate significant amounts of GluA2 if receptors remain intact under these conditions. In contrast, receptor complexes should be disrupted prior to immunoprecipitation in denatured homogenates and thus little, if any, GluA2 should coimmunoprecipitate with GluA1. Consistent with this, GluA2 coimmunoprecipitated with GluA1 from nondenatured homogenates (Fig. 2A) and levels of GluA2 in the unbound fraction were depleted to just $9 \pm 1 \%$ of input $(n=5, \quad P<0.001$ compared with IgG control unbound fraction) (Fig. 2B). GluA2 subunits did not, however, coimmunoprecipitate with GluA1 from denatured homogenates (Fig. 2C). Although GluA1 was efficiently depleted from denatured homogenates, GluA2 levels in the unbound fraction were $101 \pm 5 \%$ of input ( $n=5, P=0.82$ compared to IgG control unbound fraction) (Fig. 2D). Together, these results validate our approach, confirming that AMPARs are disrupted in denatured homogenates but remain largely intact in the nondenatured homogenates.

\section{Immunodepletion of T840 and S845-phosphorylated GluAl from denatured hippocampal homogenates}

To determine basal levels of GluA1 phosphorylation, we next measured depletion of GluA1 following immunoprecipitation of T840- or S845-phosphorylated GluA1 from denatured hippocampal homogenates (Fig. 3). Strikingly, even though 

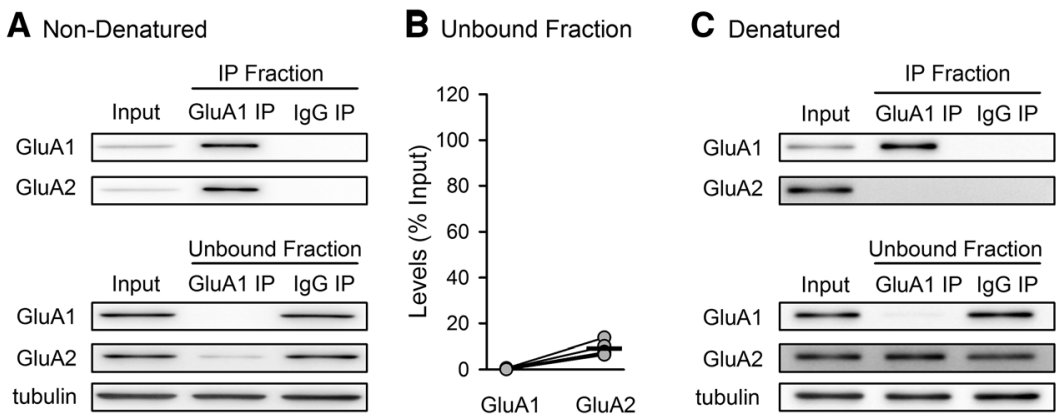

D Unbound Fraction

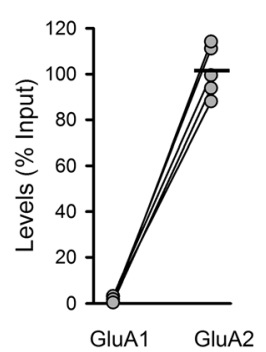

Figure 2. Immunoprecipitation of GluA1 from nondenatured and denatured hippocampal homogenates. (A) GluA2 subunits coimmunoprecipitate with GluA1 from nondenatured homogenates. Example immunoblots showing GluA1 and GluA2 levels in the input fraction, immunoprecipitated (IP) fraction (top), and unbound fraction (bottom) after immunoprecipitation with anti-GluA1 or control IgG antibodies. (B) Levels of GluA1 and GluA2 in the unbound fraction expressed as a percentage of levels in input fraction $(n=5$, lines connect results from same immunoprecipitation). (C,D) GluA2 subunits do not coimmunoprecipitate with GluA1 from denatured homogenates. Same as in panels $A$ and $B$ except that GluA1 immunoprecipitations were performed using denatured homogenates $(n=5)$. Bars indicate median values.

immunoprecipitation of T840-phosphorylated GluA1 was not complete (phospho-T840 levels in the unbound fraction were reduced to $10 \pm 2 \%$ of input, $n=5)$, GluA1 levels in the unbound fraction were reduced to $51 \pm 9 \%$ of input $(P<0.01$ compared with IgG control unbound fraction) (Fig. 3A,B). This indicates that at least $50 \%$ of GluA1 subunits in hippocampal neurons are basally phosphorylated at T840. In contrast, we were unable to detect depletion of total GluA1 subunits in the unbound fraction following immunoprecipitation of S845-phosphorylated GluA1 even though S845-phosphorylated GluA1 subunits were completely depleted from the homogenate (Fig. 3C,D). We were also unable to detect depletion of T840-phosphorylated GluA1 subunits in the unbound fraction following immunoprecipitation of S845-phosphorylated GluA1 (Fig. 3D). However, immunoprecipitation of T840-phosphorylated GluA1 reduced levels of S845-phosphorylated GluA1 subunits in the unbound fraction to $67 \pm 4 \%$ of input $(P<0.01$ compared to levels in IgG control unbound fraction) (Fig. 3B). This indicates that about one-third of the small population of S845-phosphorylated subunits is also phosphorylated at T840. Together, these findings indicate that although a substantial fraction of GluA1 subunits are basally phosphorylated at T840, relatively few subunits are phosphorylated at S845 and an even smaller fraction are phosphorylated at both of these sites. Thus, we focused on T840 phosphorylation for the remainder of our experiments.

Previous findings suggest that basal levels of GluA1 T840 phosphorylation are determined by the opposing actions of persistently active protein kinases and protein phosphatases (Lee et al. 2007; Hosokawa et al. 2015). If so, blocking protein phosphatases should significantly increase the proportion of GluA1 subunits phosphorylated at T840. To examine this we determined the proportion of GluA1 subunits phosphorylated at T840 in hippocampal slices that were either untreated or exposed to the protein phosphatase $1 / 2 \mathrm{~A}$ inhibitor cantharidin $(20 \mu \mathrm{M}$ for $1 \mathrm{~h})$. As shown in Figure 4A and B, T840-phosphorylated GluA1 levels in the input fractions increased to $182 \pm 6 \%$ of control in cantharidin-treated slices $(n=7, P<0.01)$. Depletion of GluA1 levels in the unbound fraction following immunoprecipitation of T840-phosphorylated GluA1 was also significantly enhanced $(P<0.002)$ in homogenates prepared from cantharidin-treated slices. GluA1 levels in the unbound fraction were $47 \pm 5 \%$ of input in homogenates from untreated control slices and were just $14 \pm 1 \%$ of input in homogenates prepared from cantharidintreated slices (Fig. 4C,D). Thus, in the presence of a protein phosphatase inhibitor a large proportion $(\sim 86 \%)$ of GluA1 subunits are phosphorylated at T840.

\section{Immunodepletion of T840-phosphorylated GluAl from nondenatured hippocampal homogenates}

The fact that $50 \%$ of GluA1 subunits are basally phosphorylated at T840 raises an important question. How many GluA1 subunitcontaining AMPARs in hippocampal neurons contain at least one subunit phosphorylated at T840? Because AMPARs are disrupted in denatured homogenates, the stoichiometry of subunit phosphorylation in intact AMPA receptors cannot be determined by this approach alone. Therefore, to address this question we performed immunodepletion assays using nondenatured hippocampal homogenates to immunoprecipitate intact AMPARs.

Although hippocampal neurons express a small population of homomeric receptors containing 4 GluA1 subunits, the vast majority of AMPARs are GluA1/A2 heteromeric receptors (Wenthold et al. 1996). These heteromeric receptors contain two GluA1 subunits (Mansour et al. 2001) and thus can exist in one of three stoichiometric configurations where either zero, one, or two subunits are phosphorylated at T840. Because 50\% of all GluA1 subunits are phosphorylated at T840, nearly every AMPAR in hippocampal neurons could be phosphorylated at this site if receptors contain only one T840-phosphorylated GluA1 subunit. If so, the number of subunits pulled down in the nondenatured assay, where nonphosphorylated GluA1 subunits can coimmunoprecipitate with T840-phosphorylated GluA1, would be twice that pulled down in the denatured assay, leaving GluA1 subunits completely depleted from the unbound fraction. Alternatively, if T840-phosphorylation occurs in a way such that all receptors are either doubly phosphorylated or not at all, then immunoprecipitation of T840-phosphorylated GluA1 would deplete an equal amount of GluA1 from denatured and nondenatured homogenates. A mixture of stoichiometries would lead to a number in between. Intriguingly, total GluA1 levels in the unbound fraction were also reduced by $\sim 50 \%(49 \pm 6 \%$ of input, $n=5, P<0.01$ compared with levels in control IgG unbound fraction) following immunoprecipitation of T840-phosphorylated GluA1 from nondenatured homogenates (Fig. 5). This suggests that at the receptor level T840 phosphorylation occurs in an "all or none" fashion where the multiple GluA1 subunits present in a given receptor are either all phosphorylated or all unphosphorylated at this site.

\section{Discussion}

Modulation of AMPAR ion channel properties and receptor trafficking triggered by changes in GluA1 subunit phosphorylation 
A Denatured, pT840 IP

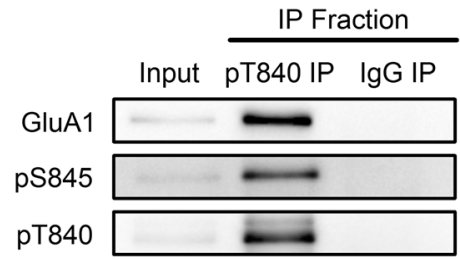

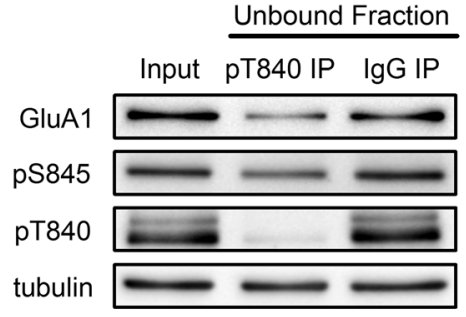

B Unbound Fraction

Probe: $\quad$ pT840

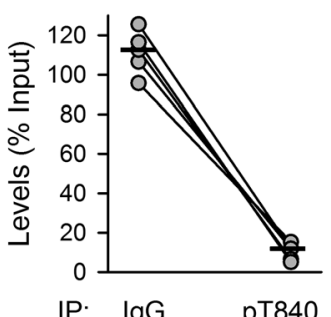

IP: $\quad \lg G$
GluA1

\section{100
80
60
40
20
$\quad 0$}

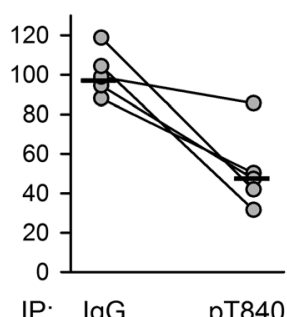

IP: $\lg G$
pS845

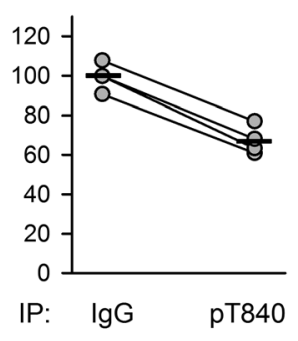

\section{Denatured, pS845 IP}
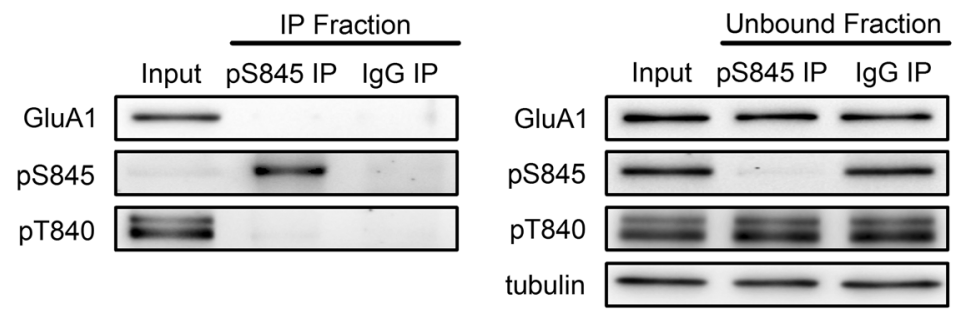

\section{Unbound Fraction}
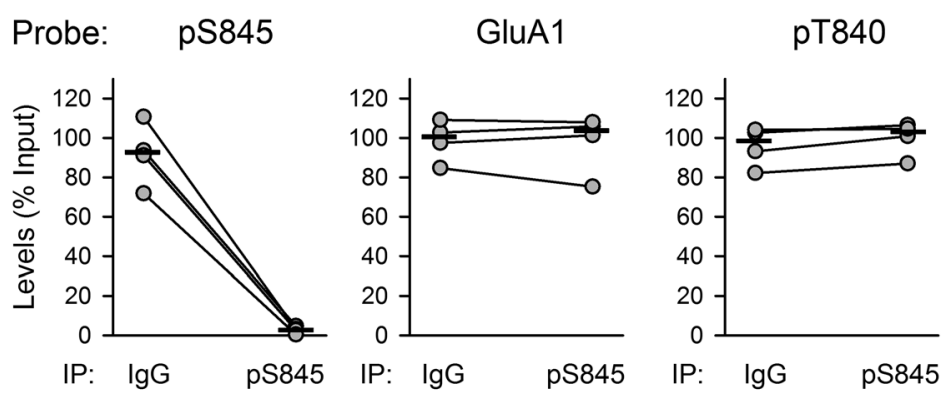

Figure 3. Immunoprecipitation of phosphorylated GluA1 from denatured hippocampal homogenates. (A) Example immunoblots showing total and phosphorylated GluA1 in immunoprecipitated (left) and unbound fractions (right) following immunoprecipitation of T840-phosphorylated GluA1. (B) Plots show levels of total and phosphorylated GluA1 in the unbound fraction following immunoprecipitations using either phospho-T840 GluA1 or control IgG antibodies ( $n=5$, lines connect results from the same homogenate). GluA1 levels in the unbound fraction were reduced to $51 \pm 9 \%$ of input following immunoprecipitation of T840-phosphorylated GluA1 $(P<0.01$ compared with levels in IgG control unbound fraction) $(C, D)$ Same as in panels $A$ and $B$ except immunoprecipitations were performed using phospho-S845 GluA1 antibodies $(n=4)$. GluA1 levels in the unbound fraction were $98 \pm 8 \%$ of the input following immunoprecipitation of $S 845$-phosphorylated GluA1 ( $P=0.41 \mathrm{com}$ pared with levels in IgG control unbound fraction). Bars in point plots indicate median values.

are thought to contribute to changes in synaptic strength induced by activity-dependent (Lee and Kirkwood 2011; Lu and Roche 2012) as well as homeostatic forms of synaptic plasticity (Goel et al. 2011; Diering et al. 2014). Moreover, phosphorylation sites in GluA1 subunits may represent important targets for protein kinases activated by modulatory neurotransmitters that regulate the induction of both long-term potentiation and LTD (Hu et al. 2007; Seol et al. 2007; Qian et al. 2012). Importantly, changes in the total number of GluA1 subunits that are phosphorylated determine the functional impact of increases or decreases in GluA1 phosphorylation and thus the ability of decreases or increases in GluA1 phosphorylation to regulate synaptic transmission is critically dependent on basal levels of subunit phosphorylation. For example, a twofold relative decrease (or increase) in phosphorylation at a particular site (measured by immunoblotting with phosphorylation site-specific antibodies) could have a strong impact if $50 \%$ of receptors are basally phosphorylated, as we report here for the T840 site in GluA1 (Fig. 3A,B). In contrast, the same relative change in subunit phosphorylation would likely have little effect if only a minor fraction of receptors were basally phosphorylated, as appears to be the case for S845 (Fig. 3C,D).

In our experiments, we used a modified version of immunodepletion assays that have previously been used to determine the subunit composition of AMPARs (Wenthold et al. 1996; Sans et al. 2003; Reimers et al. 2011) to examine GluA1 phosphorylation at the level of individual GluA1 subunits and intact receptors. Strikingly, although S845phosphorylated GluA1 can readily be detected on blots probed with a phospho-S845 specific antibody, immunoprecipitation of S845-phosphorylated GluA1 had no measurable effect on GluA1 levels in the unbound fraction. This suggests that few GluA1 subunits are basally phosphorylated at this site in hippocampal neurons. In contrast, our results indicate that T840-phosphorylated subunits are abundant, with $\sim 50 \%$ of GluA1 subunits basally phosphorylated at this site. Interestingly, GluA1 levels in the unbound fraction were also reduced by $\sim 50 \%$ following immunoprecipitation of T840-phosphorylated GluA1 from nondenatured homogenates, where nonphosphorylated GluA1 subunits in the same receptor complexes can coimmunoprecipitate with T840phophorylated GluA1. The similar depletion of GluA1 from denatured and nondenatured homogenates following immunoprecipitation of T840-phosphorylated GluA1 suggests that many of the T840-phosphorylated AMPARs have both (or all) of their GluA1 subunits phosphorylated at this site. It is important to recognize, however, that some receptor complexes could be dissociated even under nondenaturing conditions. Thus, our 
A pT840 IP
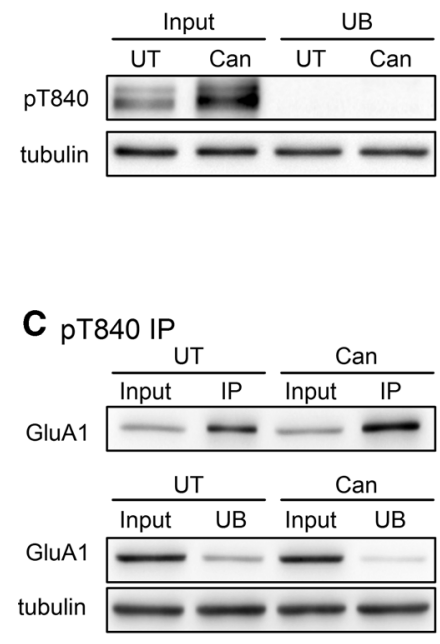

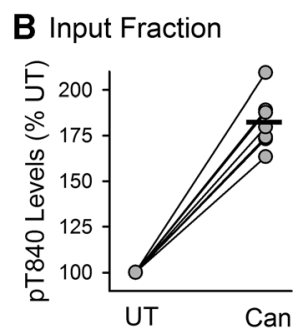

D Unbound Fraction

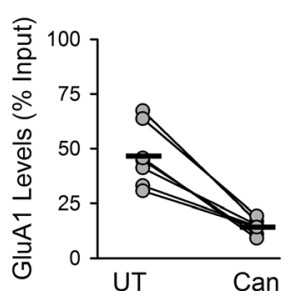

Figure 4. Phospho-T840 immunodepletion assays using denatured homogenates prepared from hippocampal slices maintained in vitro. Hippocampal slices obtained from the same animal were either left untreated (UT) or exposed to $20 \mu \mathrm{M}$ cantharidin (Can) for $1 \mathrm{~h}(n=7)$. (A) Immunoblots showing phospho-T840 GluA1 levels in the input and unbound (UB) fractions from untreated control and cantharidin-treated slices. (B) Levels of T840-phosphorylated GluA1 in the input fractions from untreated control and cantharidin-treated slices. (C) Immunoblots show GluA1 in immunoprecipitated (IP) fraction (top) and unbound fractions (bottom) from untreated control and cantharidin-treated slices. (D) Levels of total GluA1 in the unbound fraction following immunoprecipitation of T840-phosphorylated GluA1 from homogenates prepared from untreated control and cantharidin treated slices. Lines in $B$ and $D$ connect results from the same experiment. Bars indicate median values.

measurements may underestimate the population of receptors containing both T840-phosphorylated and nonphosphorylated GluA1 subunits. However, the strong depletion of GluA2 subunits following immunoprecipitation of GluA1 from nondenatured homogenates (Fig. 2B), suggests that AMPARs remain largely intact under these conditions.

Recent findings from experiments using Phos-tag gel electrophoresis to measure the proportion of GluA1 subunits basally phosphorylated at T840 and S845 in hippocampal neurons suggest that $<0.02 \%$ of GluA1 subunits are phosphorylated at S845 and only $4 \%$ of all subunits are phosphorylated at T840 (Hosokawa et al. 2015; see Kinoshita et al. 2015 for a description of Phos-tag gel electrophoresis). It is unclear why Phos-tag gel electrophoresis and immunodepletion assays give very different answers regarding the proportion of GluA1 subunits basally phosphorylated at T840 in hippocampal neurons. It is intriguing, however, that both approaches indicate that only a small proportion of GluA1 subunits are basally phosphorylated at S845 and that T840-phosphorylated subunits are much more abundant than S845-phosphorylated subunits. Moreover, Phos-tag gel electrophoresis and immunodepletion assays provide similar numbers for the proportion of GluA1 subunits phosphorylated at T840 in the presence of protein phosphatase inhibitors $(80 \%$ and $86 \%$, respectively, see
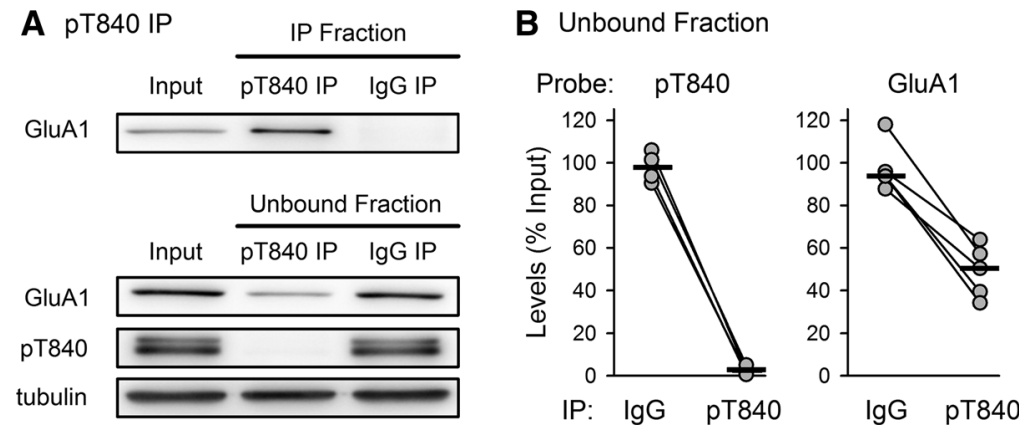

Fig. 4; Hosokawa et al. 2015). However, in our experiments the increase in the proportion of GluA1 subunits phosphorylated at T840 induced by inhibiting protein phosphatases was associated with a less than twofold increase in relative levels of T840 phosphorylation while a 19-fold increase in relative phosphorylation was seen in the experiments of Hosokawa et al. (2015). Clearly, a 19-fold increase in relative T840 phosphorylation would be impossible if $50 \%$ of GluA1 subunits are basally phosphorylated at this site but could occur if only $4 \%$ of subunits are. Thus, our results and those of Hosokawa et al. (2015) are consistent in that blocking protein phosphatases induces a modest increase in relative T840 phosphorylation under conditions where basal levels of GluA1 T840 phosphorylation are high (our experiments) and a much more robust increase under conditions where the basal level of GluA1 phosphorylation is much lower (Hosokawa et al. 2015). This suggests that differences in starting material, perhaps due to changes in protein phosphorylation during sample preparation, could account for the very different estimates of the proportion of GluA1 subunits basally phosphorylated at T840. Importantly, protein kinases and phosphatases will be inactivated in experiments where homogenates were denatured prior to immunoprecipitation and in control experiments we found no evidence that GluA1 T840 or S845 phosphorylation is altered during immunoprecipitation under nondenatured conditions (see Materials and Methods). This indicates that the methods we used for immunoprecipitation preserved GluA1 phosphorylation.

Although more work is required to resolve these issues, results from both Phos-tag gels and immunodepletion assays suggest that few GluA1 subunits are basally phosphorylated at S845, which is difficult to reconcile with the notion that dephosphorylation of this site has a crucial role in LTD. Low basal levels of GluA1 S845 phosphorylation also seem inconsistent with the idea that increased S845 phosphorylation is responsible for the ability of some modulatory neurotransmitters to facilitate the induction of LTP. It is important to note, however, that our use of crude hippocampal homogenates makes it impossible to rule out the possibility that different proportions of S845-phosphorylated GluA1 exist in different cellular compartments, cell types, and hippocampal regions. However, our observations (and those of Hosokawa et al. 2015) do help to explain the paradoxical finding that under some experimental conditions pharmacological activation of NMDARs can induce robust and persistent decreases in $\$ 845$ phosphorylation (as detected by immunoblotting with phospho-specific antibodies) yet have no lasting effect on synaptic strength (Gray et al. 2014). In contrast, the induction of shortterm depression of synaptic transmission by bath application of 
NMDA induces a transient dephosphorylation of GluA1 at T840 that recovers with a time course similar to the recovery of synaptic transmission. Furthermore, this site is persistently dephosphorylated following the induction of LTD by a chemical induction protocol (Delgado et al. 2007; Gray et al. 2014). Thus, unlike S845, dephosphorylation of T840 closely parallels changes in synaptic strength during both short-term and long-term decreases in synaptic strength. Moreover, unlike S845, a substantial proportion of GluA1 subunits are basally phosphorylated at T840. Together, these findings suggest that T840 represents an important site where protein phosphatases and protein kinases can act to regulate AMPAR-mediated synaptic transmission in hippocampal neurons.

\section{Materials and Methods}

\section{Sample preparation from intact hippocampi and hippocampal slices}

Standard methods approved by the University of California, Los Angeles Institutional Animal Care and Use Committee were used to obtain intact hippocampi or hippocampal slices from 8-12 wk old C57Bl/ 6 male mice. Briefly, animals were anesthetized with isoflurane and killed by cervical dislocation. The brain was then rapidly removed and placed into cold $\left(4^{\circ} \mathrm{C}\right)$, oxygenated $\left(95 \% \mathrm{O}_{2} / 5 \% \mathrm{CO}_{2}\right)$ artificial cerebral spinal fluid (ACSF) containing $124 \mathrm{mM} \mathrm{NaCl}, 4.4 \mathrm{mM} \mathrm{KCl}, 25 \mathrm{mM} \mathrm{Na}_{2} \mathrm{HCO}_{3}, 1$ $\mathrm{mM} \mathrm{NaH}_{2} \mathrm{PO}_{4}, 1.2 \mathrm{mM} \mathrm{MgSO}_{4}, 2 \mathrm{mM} \mathrm{CaCl}_{2}$, and $10 \mathrm{mM}$ glucose. Hippocampi were then either snap-frozen and stored at $-80^{\circ} \mathrm{C}$ for use in immunoprecipitations or used to prepare $400-\mu \mathrm{m}$ thick slices that were then maintained in an interface-type chamber perfused $(2-3 \mathrm{~mL} / \mathrm{min})$ with warm $\left(30^{\circ} \mathrm{C}\right)$ ACSF. Slices were allowed to recover for $2 \mathrm{~h}$ and then either left untreated or exposed to ACSF containing the protein phosphatase $1 / 2 \mathrm{~A}$ inhibitor cantharidin $(20 \mu \mathrm{M}, 1 \mathrm{~h})$. Slices were then transferred to prefrozen microcentrifuge tubes placed in a bed of crushed dry ice and stored at $-80^{\circ} \mathrm{C}$.

\section{Immunodepletion assays}

For immunoprecipitations using denatured proteins, one hippocampus (or six hippocampal slices) were homogenized in a denaturing lysis buffer containing $50 \mathrm{mM}$ Tris ( $\mathrm{pH}=7.4), 5 \mathrm{mM}$ EDTA, $1 \%$ SDS, and $10 \mu \mathrm{M}$ cantharidin that was supplemented with cocktails of both protein phosphatase inhibitors (Phosphatase Inhibitor Cocktails II and III from Sigma-Aldrich) and protease inhibitors (Sigma-Aldrich). Samples were sonicated, boiled for $5 \mathrm{~min}$, and then allowed to cool at room temperature for $5 \mathrm{~min}$. The homogenate was then diluted 10 -fold in dilution buffer (50 mM Tris, $1 \%$ Triton X-100, 5 mM EDTA, $300 \mathrm{mM} \mathrm{NaCl}$, $\mathrm{pH}=7.4)$, placed on ice for $5 \mathrm{~min}$, and centrifuged $(14,000 \mathrm{~g}$, $4^{\circ} \mathrm{C}$ ) for $15 \mathrm{~min}$. For the input sample, a portion of the supernatant was removed, maintained at $4^{\circ} \mathrm{C}$ overnight and then boiled the next day in an equal volume of $2 \times$ loading buffer $(0.5 \mathrm{M}$ Tris $-\mathrm{HCl}, 4.4 \%$ SDS, $20 \%$ glycerol, $2 \%$ mercaptoethanol, $\mathrm{pH}=$ 6.8). Immunoprecipitations were performed by incubating another portion of the supernatant with $4 \mu \mathrm{g}$ of phospho-T840, phospho-S845 or total GluA1, antibodies for $3-4 \mathrm{~h}$ at $4^{\circ} \mathrm{C}$ followed by an overnight incubation with Protein A Plus agarose beads (Pierce) at $4^{\circ} \mathrm{C}$. Beads were then pelleted by centrifugation and the supernatant (unbound fraction) was removed and boiled in an equal volume of $2 \times$ loading buffer. The beads were washed three times in a buffer containing $50 \mathrm{mM}$ Tris $(\mathrm{pH}=7.4), 300 \mathrm{mM}$ $\mathrm{NaCl}, 5 \mathrm{mM}$ EGTA, and $0.1 \%$ Triton X-100 and then resuspended in $1 \times$ loading buffer and boiled for $10 \mathrm{~min}$. Beads were then pelleted by centrifugation and the supernatant (immunoprecipitated sample) was collected.

For immunoprecipitation of nondenatured proteins, hippocampi or hippocampal slices were homogenized in a modified RIPA buffer containing $50 \mathrm{mM}$ Tris (pH 7.4), $150 \mathrm{mM} \mathrm{NaCl}, 1 \%$ NP-40, 0.5\% DOC, 0.1\% SDS, 10 mM EGTA, 10 mM EDTA, $25 \mathrm{mM}$ sodium pyrophosphate, $10 \mu \mathrm{M}$ cantharidin and cocktails of protein phosphatase and protease inhibitors (see above). A portion of the homogenate was maintained at $4^{\circ} \mathrm{C}$ overnight and then boiled the next day in an equal volume of $2 \times$ loading buffer (input fraction). Part of the remaining homogenate was then used for immunoprecipitations as described above.

To confirm that GluA1 phosphorylation is not altered during the overnight incubation of nondenatured homogenates with antibodies and agarose beads, we measured phospho-GluA1 levels in samples from the same homogenate that were either immediately mixed with $2 \times$ loading buffer and boiled or left overnight at $4^{\circ} \mathrm{C}$ and mixed with $2 \times$ loading buffer and boiled the next day. Levels of T840- and S845-phosphorylated GluA1 in samples maintained overnight were $94 \pm 2 \%$ and $97 \pm 8 \%$ of those in samples denatured immediately after homogenization, respectively $(n=3$, data not shown). This indicates that GluA1 phosphorylation is preserved during the immunoprecipitation protocol.

\section{Western immunoblotting}

Proteins (equal volumes or protein concentrations per lane) were separated by SDS-PAGE ( $4 \%$ and $12 \%$ acrylamide stacking and resolving gels, respectively) and transferred to $0.2-\mu \mathrm{m}$ nitrocellulose membranes using standard procedures. Membranes were blocked in Tris-buffered saline containing 0.05\% Tween-20 (TBST) plus $4 \%$ nonfat dry milk for $1 \mathrm{~h}$ and then incubated overnight at $4^{\circ} \mathrm{C}$ in TBST containing 4\% nonfat dry milk and phospho-T840, phospho-S845 or total GluA1 antibodies. Blots were then washed three times with TBST and incubated for $2-4 \mathrm{~h}$ at room temperature in TBST containing $4 \%$ nonfat dry milk and an anti-mouse or anti-rabbit HRP-conjugated secondary antibody. Immunoreactive bands were visualized using enhanced chemiluminesence (ProtoGlow ECL, National Diagnostics). Image acquisition and analysis were done using a 12-bit cooled CCD camera and Image Lab software (Bio-Rad). For quantification of signals from unbound fractions the blots were reprobed with an anti-tubulin antibody. Density values for phospho- and total GluA1 bands were then normalized to levels of tubulin in each lane to control for potential variations in loading.

\section{Reagents and antibodies}

Cantharidin (Abcam) was prepared as a $20 \mathrm{mM}$ stock solution in DMSO. All other chemicals were obtained from Sigma-Aldrich. Phospho-T840 (1:2,000) and total GluA1 antibodies (1:2000, rabbit monoclonal EPR5479) were obtained from Abcam and the phospho-S845 antibody (1:1000) was obtained from Millipore. Monoclonal antibodies against a neuronal specific isoform (BIII) of tubulin $(1: 20,000$, Clone 2G10) and AMPAR GluA2 subunits $(1: 1000-500$, Clone N52A/42) were obtained from Sigma-Aldrich and the UC Davis/NIH NeuroMab facility, respectively. Control immunoprecipitations were performed using a nonimmune rabbit IgG obtained from Santa Cruz Biotechnology. Horseradish peroxidase conjugated secondary antibodies $(1: 2,000)$ were obtained from GE Healthcare. The phospho-T840 and phospho-S845 GluA1 antibodies used in these experiments have been extensively characterized by us (Delgado et al. 2007; Gray et al. 2014) and others (Hosokawa et al. 2015; Toda and Huganir 2015) and do not recognize nonphosphorylated GluA1 or GluA1 phosphorylated at other sites.

\section{Statistics}

Results are presented as mean \pm SEM. Summary plots in figures show results from all individual experiments. Because normality for small sample sizes could not be guaranteed, resampling statistics (bootstrapping), performed using routines written in $\mathrm{R}$, were used to determine statistical significance (Manly 2007). $P<0.05$ was considered to be significant.

\section{Acknowledgments}

This study was supported by a grant from the National Institutes of Mental Health (T.J.O.). W.E.B. was supported by grant 
T32NS007101 and R.G. was supported by an ARCS Foundation Scholar Award.

\section{References}

Babiec WE, Guglietta R, Jami SA, Morishita W, Malenka RC, O’Dell TJ. 2014. Ionotropic NMDA receptor signaling is required for the induction of long-term depression in the mouse hippocampal CA1 region. J Neurosci 34: 5285-5290.

Cheng D, Hoogenraad CC, Rush J, Ramm E, Schlager MA, Duong DM, Xu P, Wijayawardana SR, Hanfelt J, Nakagawa T, et al. 2006. Relative and absolute quantification of postsynaptic density proteome isolated from rat forebrain and cerebellum. Mol Cell Proteomics 5: 1158-1170.

Delgado JY, Coba M, Anderson CNG, Thompson KR, Gray EE, Heusner CL, Martin KC, Grant SG, O’Dell TJ. 2007. NMDA receptor activation dephosphorylates AMPA receptor glutamate receptor 1 subunits at threonine 840. J Neurosci 27: 13210-13221.

Derkach VA, Oh MC, Guire ES, Soderling TR. 2007. Regulatory mechanisms of AMPA receptors in synaptic plasticity. Nat Rev Neurosci 8: 101-113.

Diering GH, Gustina AS, Huganir RL. 2014. PKA-GluA1 coupling via AKAP5 controls AMPA receptor phosphorylation and cell-surface targeting during bidirectional homeostatic plasticity. Neuron 84: 790-805.

Ehlers MD. 2000. Reinsertion or degradation of AMPA receptors determined by activity-dependent endocytic sorting. Neuron 28: $511-525$.

Granger AJ, Nicoll RA. 2014. LTD expression is independent of glutamate receptor subtype. Front Synaptic Neurosci 6: 15.

Gray EE, Guglietta R, Khakh BS, O'Dell TJ. 2014. Inhibitory interactions between phosphorylation sites in the $\mathrm{C}$ terminus of $\alpha$-Amino-3-hydroxy-5-methyl-4-isoxazolepropionic acid-type glutamate receptor GluA1 subunits. J Biol Chem 289: 14600-14611.

Goel A, Xu LW, Snyder KP, Song L, Goenaga-Vazquez Y, Megill A, Takamiya K, Huganir RL, Lee HK. 2011. Phosphorylation of AMPA receptors is required for sensory deprivation-induced homeostatic synaptic plasticity. PLoS One 6: e18264.

He K, Lee A, Song L, Kanold PO, Lee HK. 2011. AMPA receptor subunit GluR1 (GluA1) serine-845 site is involved in synaptic depression but not in spine shrinkage associated with chemical long-term depression. J Neurophysiol 105: 1897-1907.

Hosokawa T, Mitsushima D, Kaneko R, Hayashi Y. 2015. Stoichiometry and phosphoisotypes of hippocampal AMPA-type glutamate receptor phosphorylation. Neuron 85: 60-67.

$\mathrm{Hu}$ H, Real E, Takamiya K, Kang MG, Ledoux J, Huganir RL, Malinow R. 2007. Emotion enhances learning via norepinephrine regulation of AMPA-receptor trafficking. Cell 131: 160-173.

Jenkins MA, Wells G, Bachman J, Snyder JP, Jenkins A, Huganir RL, Oswald RE, Traynelis SF. 2014. Regulation of GluA1 $\alpha$-amino-3-hydroxy-5-methyl-4-isoxazolepropionic acid receptor function by protein kinase $\mathrm{C}$ at serine-818 and threonine-840. $\mathrm{Mol}$ Pharm 85: 618-629.

Kinoshita E, Kinoshita-Kikuta E, Koike T. 2015. Advances in Phos-tag-based methodologies for separation and detection of the phosphoproteome. Biochim Biophys Acta 1854: 601-608.

Lee HK, Kirkwood A. 2011. AMPA receptor regulation during synaptic plasticity in hippocampus and cortex. Semin Cell Dev Biol 22: 514-520.

Lee H-K, Kameyama K, Huganir RL, Bear MF. 1998. NMDA induces long-term synaptic depression and dephosphorylation of the GluR1 subunit of AMPA receptors in hippocampus. Neuron 21: 1151-1162.

Lee HK, Barbarosie M, Kameyama K, Bear MF, Huganir RL. 2000. Regulation of distinct AMPA receptor phosphorylation sites during bidirectional synaptic plasticity. Nature 405: 955-959.
Lee H-K, Takamiya K, Han JS, Man H, Kim CH, Rumbaugh G, Yu S, Ding L, He C, Petralia RS, et al. 2003. Phosphorylation of the AMPA receptor GluR1 subunit is required for synaptic plasticity and retention of spatial memory. Cell 112: 631-643.

Lee HK, Takamiya K, Kameyama K, He K, Yu S, Rossetti L, Wilen D, Huganir RL. 2007. Identification and characterization of a novel phosphorylation site on the GluR1 subunit of AMPA receptors. Mol Cell Neurosci 36: 86-94.

Lee HK, Takamiya K, He K, Song L, Huganir RL. 2010. Specific roles of AMPA receptor subunit GluR1 (GluA1) phosphorylation sites in regulating synaptic plasticity in the CA1 region of hippocampus. J Neurophysiol 103: $479-489$.

Lu W, Roche KW. 2012. Posttranslational regulation of AMPA receptor trafficking and function. Curr Opin Neurobiol 22: 470-479.

Lu W, Shi Y, Jackson AC, Bjorgan K, During MJ, Sprengel R, Seeburg PH, Nicoll RA. 2009. Subunit composition of synaptic AMPA receptors revealed by a single-cell genetic approach. Neuron 62: 254-268.

Man HY, Sekine-Aizawa Y, Huganir RL. 2007. Regulation of $\alpha$-amino-3-hydroxy-5-methyl-4-isoxazolepropionic acid receptor trafficking through PKA phosphorylation of the Glu receptor 1 subunit. Proc Natl Acad Sci 104: 3579-3584.

Manly BFJ. 2007. Randomization, bootstrap and Monte Carlo methods in biology. Chapman \& Hall/CRC, Boca Raton.

Mansour M, Nagarajan N, Nehring RB, Clements JD, Rosenmund C. 2001. Heteromeric AMPA receptors assemble with a preferred subunit stoichiometry and spatial arrangement. Neuron 32: 841-853.

Oh MC, Derkach VA, Guire ES, Soderling TR. 2006. Extrasynaptic membrane trafficking regulated by GluR1 serine 845 phosphorylation primes AMPA receptors for long-term potentiation. J Biol Chem 281: $752-758$

Qian H, Matt L, Zhang M, Nguyen M, Patriarchi T, Koval OM, Anderson ME, He K, Lee HK, Hell JW. 2012. $\beta 2$-Adrenergic receptor supports prolonged $\theta$ tetanus-induced LTP. J Neurophysiol 107: 2703-2712.

Reimers JM, Milovanovic M, Wolf ME. 2011. Quantitative analysis of AMPA receptor subunit composition in addiction-related brain regions. Brain Res 1367: 223-233.

Sans N, Vissel B, Petralia RS, Wang YX, Chang K, Royle GA, Wang CY, O'Gorman S, Heinemann SF, Wenthold RJ. 2003. Aberrant formation of glutamate receptor complexes in hippocampal neurons of mice lacking the GluAR2 AMPA receptor subunit. J Neurosci 23: 9367-9373.

Selcher JC, Xu W, Hanson JE, Malenka RC, Madison DV. 2012. Glutamate receptor subunit GluA1 is necessary for long-term potentiation and synapse unsilencing, but not long-term depression in mouse hippocampus. Brain Res 1435: 8-14.

Seol GH, Ziburkus J, Huang S, Song L, Kim IT, Takamiya K, Huganir RL, Lee HK, Kirkwood A. 2007. Neuromodulators control the polarity of spike-timing-dependent synaptic plasticity. Neuron 55: 919-929.

Shepherd JD, Huganir RL. 2007. The cell biology of synaptic plasticity: AMPA receptor trafficking. Annu Rev Cell Dev Biol 23: 613-643.

Toda AM, Huganir RL. 2015. Regulation of AMPA receptor phosphorylation by the neuropeptides PACAP38. Proc Natl Acad Sci 112: 6712-6717.

Traynelis SF, Wollmuth LP, McBain CJ, Menniti FS, Vance KM, Ogden KK, Hansen KB, Yuan H, Myers SJ, Dingledine R. 2010. Glutamate receptor ion channels: structure, regulation, and function. Pharmacol Rev 62: 405-496.

Wenthold RJ, Petralia RS, Blahos J II, Niedzielski AS. 1996. Evidence for multiple AMPA receptor complexes in hippocampal CA1/CA2 neurons. J Neurosci 16: 1982-1989.

Received October 13, 2015; accepted in revised form January 12, 2016. 


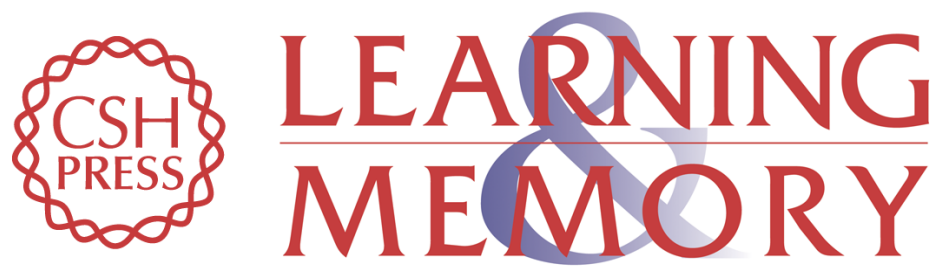

\section{Basal levels of AMPA receptor GluA1 subunit phosphorylation at threonine $\mathbf{8 4 0}$ and serine $\mathbf{8 4 5}$ in hippocampal neurons}

Walter E. Babiec, Ryan Guglietta and Thomas J. O'Dell

Learn. Mem. 2016, 23:

Access the most recent version at doi:10.1101/Im.040675.115

\begin{aligned} & \hline References $\begin{array}{l}\text { This article cites } 34 \text { articles, } 11 \text { of which can be accessed free at: } \\ \text { http://learnmem.cshlp.org/content/23/4/127.full.html\#ref-list-1 }\end{array} \\ & \begin{array}{r}\text { Creative } \\ \text { Commons } \\ \text { License }\end{array} \begin{array}{l}\text { This article is distributed exclusively by Cold Spring Harbor Laboratory Press for the } \\ \text { first } 12 \text { months after the full-issue publication date (see } \\ \text { http://learnmem.cshlp.org/site/misc/terms.xhtml). After } 12 \text { months, it is available under } \\ \text { a Creative Commons License (Attribution-NonCommercial } 4.0 \text { International), as } \\ \text { described at http://creativecommons.org/licenses/by-nc/4.0/. }\end{array} \\ & \begin{array}{c}\text { Receive free email alerts when new articles cite this article - sign up in the box at the } \\ \text { top right corner of the article or click here. }\end{array} \\ &$ Service \end{aligned} 